\title{
Suscetibilidade do capim-colonião e de cultivares de milho ao flúor
}

\author{
Rimena Ramos Domingues ( $\left.{ }^{1}\right)$; Geisa Lima Mesquita $\left({ }^{1 *}\right)$; Heitor Cantarella $\left({ }^{2}\right)$; Dirceu de Mattos \\ Júnior $\left(^{3}\right)$
}

(1) Instituto Agronômico (IAC), Pós-Graduação em Agricultura Tropical e Subtropical, Caixa Postal 28, 13020-902 Campinas (SP), Brasil.

(2) IAC, Centro de Solos, Av. Barão de Itapura, 1481, 13020-902 Campinas (SP), Brasil.

(3) IAC, Centro de Citricultura Sylvio Moreira, 13490-970 Cordeirópolis (SP), Brasil.

(*) Autor correspondente: gelm_1@hotmail.com

Recebido: 25/out./2010; Aceito: 7/jun./2011.

\begin{abstract}
Resumo
A emissão de fluoretos à atmosfera oriunda da produção de superfosfatos e de cerâmica tem causado preocupação pelo efeito tóxico às plantas, contudo são poucos os estudos desenvolvidos acerca do problema com espécie de interesse econômico agrícola. Desenvolveu-se o estudo para avaliar o efeito do flúor (F) atmosférico em plantas de capim-colonião e de cultivares de milho, utilizando como referência espécies bioindicadoras do tipo sensível e tolerante. As plantas foram expostas à contaminação pelo $\mathrm{F}$ atmosférico por curtos períodos durante 32 dias em sistema de nebulização com 0,16 mol $\mathrm{L}^{-1}$ de ácido fluorídrico no ambiente interno de uma câmara $\left(\sim 0,20 \mathrm{mmol} \mathrm{m}^{-3} \mathrm{de} \mathrm{F}\right)$, havendo um controle não exposto, com quatro repetições. A exposição das plantas ao $\mathrm{F}$ causou aumento da concentração do elemento nas folhas até $60 \mathrm{mg} \mathrm{kg}^{-1}$ para o capim-colonião, e entre $100 \mathrm{mg} \mathrm{kg}^{-1}$ nas folhas novas e $170 \mathrm{mg} \mathrm{kg}^{-1}$ nas folhas velhas para quatro cultivares de milho, o que demonstrou o efeito cumulativo do elemento no ambiente. Sintomas visuais da toxicidade foram observados nas plantas e se caracterizaram pela ocorrência de cloroses e necroses na lâmina foliar. O capim-colonião é uma espécie bastante sensível ao poluente no ar. As cultivares de milho DKB 390 e Ômega 8315 também são mais sensíveis ao F quando comparadas às AG7088 e 2B707. Os teores de clorofila a nas plantas foram mais afetados pelo $\mathrm{F}$ em relação aos teores de clorofila b.
\end{abstract}

Palavras-chave: Panicum maximum Jacq.; Zea mays L.; bioindicadoras; fitotoxicidade; clorofila.

\section{Susceptibility of guineagrass and corn varieties to fluoride}

\section{Abstract}

The emission of fluorides to the atmosphere arising from the production of superphosphate and ceramics has caused concern because of toxic effects on plants. However, few studies have been developed about fluoride (F) pollution with agricultural crops. A study evaluated the effect of atmospheric $F$ in guinea grass and maize plants, using reference bioindicator plants of the type sensitive and tolerant. The plants were exposed to atmospheric contamination by $\mathrm{F}$ for short periods during 32 days in a misting system delivering $0.16 \mathrm{~mol} \mathrm{~L}^{-1}$ of hydrofluoric acid inside a chamber $\left(\sim 0.20 \mathrm{mmol} \mathrm{m}^{-3}\right.$ of F). Unexposed plants (control) were also evaluated, with four replications. Exposure of plants to $\mathrm{F}$ caused an increase in leaf fluoride concentration up to $60 \mathrm{mg} \mathrm{kg}^{-1}$ for guinea grass and $100 \mathrm{mg} \mathrm{kg}^{-1}$ in the new leaves and $170 \mathrm{mg} \mathrm{kg}^{-1}$ in the old leaves for four varieties of maize, which demonstrated the cumulative effect of the element in the environment. Visual symptoms of toxicity were observed in plants and characterized by occurrence of chlorosis and necrosis on leaf blades. The guinea grass proved to be a species very sensitive to air pollution. The maize varieties DKB 390 and Omega 8315 were more sensitive to F when compared to the AG7088 and 2B707 ones. Chlorophyll a in plants was more affected by the $\mathrm{F}$ in relation to the contents of chlorophyll b.

Key words: Panicum maximum Jacq.; Zea mays L.; bioindicators; fitotoxicity; chlorophyll content.

\section{INTRODUÇÃO}

No Brasil, as emissóes atmosféricas de F ocorrem mais frequentemente no entorno de polos industriais de grandes incineradoras, fundição de alumínio e outros metais não ferrosos, de produção de adubos fosfatados e de pisos e revestimentos cerâmicos; tais atividades geram compostos reativos, como o ácido fluorídrico (HF) e o tetrafluoreto de silício $\left(\mathrm{SiF}_{4}\right)$ que são liberados pelo aquecimento de rochas e materiais terrosos a altas temperaturas (Arndt et al., 1995; Oliva e Figueiredo, 2005).

$\mathrm{Na}$ atmosfera, o F é absorvido pelas folhas através dos estômatos e, em menores proporções, pela cutícula e lenticelas (Arndt et al., 1995). O elemento se dissolve na fase aquosa da cavidade substomatal e se move na 
forma iônica através dos espaços do apoplasto do mesofilo foliar com a corrente transpiratória até as margens das folhas, onde se acumula (ARNDT et al., 1995). O F causa injúrias tipicamente caracterizadas por necroses nos ápices e nas margens das folhas, mas também afeta processos fisiológicos e bioquímicos importantes na planta, como alterações do estado nutricional, diminuição do conteúdo de clorofila, danos nos estômatos. Este conjunto de fatores reduz a fotossíntese das plantas expostas e, consequentemente, o desenvolvimento e a produçáo (Weinstein, 1977; Divan JR. et al., 2007). No solo, o F é encontrado, na sua maior parte, combinado formando espécies químicas insolúveis, fato que explica a baixa absorção pelas raízes (MACÊDo e MorRIL, 2008).

Assim, em decorrência da reatividade do HF no ambiente, prejuízos às plantas foram constatados para gramíneas (Oliva e Figueiredo, 2005) e soja em Minas Gerais (Bustamante et al., 1993) e para espécies arbóreas na Mata Atlântica (Kuumpr et al., 1996). Estudos ampliaram a base do conhecimento acerca de outras espécies frutíferas e forrageiras como bioindicadoras da poluição ambiental sob condiçóes de chuva simulada (SANT'ANNASantos e Azevedo, 2007; Oliva e Figueiredo, 2005; Divan JR. et al., 2007; Pita-Barbosa et al., 2009). Nessas condiçóes ocorre contato direto do ácido e a lâmina foliar, podendo intensificar as injúrias causadas pelo F. No entanto, o assunto continua em foco, devido aos problemas causados em culturas próximas a áreas industriais, como observado sobre a produção de milho (ForTes et al., 2003) e de cana-de-açúcar (Отто et al., 2007) no campo. Apesar da importância do tema, ainda se dispóe de informações limitadas em condições de baixas concentraçôes atmosféricas de $\mathrm{F}$ e também na distinção de cultivares da mesma espécie de regiōes tropicais, que se mostrem mais tolerantes aos danos causados pelo elemento (WeInstein e Davison, 2004).

Nesse contexto, o objetivo do trabalho foi avaliar o efeito da exposição do capim-colonião e de cultivares de milho ao $\mathrm{F}$ atmosférico sobre o estado nutricional e a produçáo de massa seca das plantas em condiçóes controladas, utilizando espécies vegetais bioindicadoras ao $\mathrm{F}$ como referência.

\section{MATERIAL E MÉTODOS}

Foram estudados o capim-colonião (Panicum maximum Jacq. Cv. Colonião) e o milho (Zea mays L.). Este último, com duas cultivares consideradas sensíveis (DKB 390 e Ômega NBX8315) e duas tolerantes à toxicidade de F (AG7088 e 2B707), verificado devido à ocorrência de sintomas visuais nas folhas de plantas localizadas próximo a áreas de industriais emitentes de $\mathrm{F}$ na atmosfera (Duarte et al., 2009). O gladíolo (Gladiolus spp. Var. White Goddess) (Klumpr et al., 1997) e o azevém
(Lolium multiflorum Lam.) (Franzaring et al., 2007) foram utilizados como espécies bioindicadoras sensível e tolerante ao $\mathrm{F}$ respectivamente. As plantas foram desenvolvidas em vasos de plástico, com capacidade para $5 \mathrm{~L}$, preenchidos com terra seca ao ar, passada em peneira de malha de $0,4 \mathrm{~cm}$ de abertura, coletada da camada arável de um solo do tipo Latossolo Vermelho-Escuro textura média $\left[\mathrm{MO}=34 \mathrm{~g} \mathrm{dm}^{-3} ; \mathrm{pH}\left(\mathrm{CaCl}_{2}\right)=5,7\right.$, CEC $=88,9 \mathrm{mmol}_{c} \mathrm{dm}^{-3}$ e saturação por bases $(\mathrm{V})=69 \%$ de acordo com RaIJ et al. (2001), e argila $\left.=300 \mathrm{~g} \mathrm{~kg}^{-1}\right]$. No preparo do solo foi misturado uréia $\left(0,667 \mathrm{~g} \mathrm{~L}^{-1}\right)$ disponibilizando $150 \mathrm{mg} \mathrm{dm}^{-3} \mathrm{de} \mathrm{N}$; 2,44 g de superfostato triplo, disponibilizando $79 \mathrm{mg} \mathrm{dm}^{-3}$ de $\mathrm{P}$. O manejo de nutrientes foi feito com a aplicação de solução nutritiva ao solo, cujas concentraçôes em $\mathrm{mg} \mathrm{dm}^{-3}$ de solo, foram: P (109), K (160), Ca (160), Mg (60), S (40), B $(0,43), \mathrm{Fe}(1,8), \mathrm{Mn}(3,33), \mathrm{Zn}(3,33), \mathrm{Cu}(1,00)$ e Mo $(0,10)$. A aplicação da soluçáo ocorreu 1 a 2 vezes por mês procurando-se adequar a demanda da planta com o crescimento, levando-se em conta o conteúdo de nutrientes na massa seca das plantas estudadas e a análise química inicial do solo. No período inicial, após o plantio das espécies, a umidade dos vasos foi mantida a 70\% da capacidade de retenção de água, e posteriormente, a 50\%-60\% da capacidade de retenção, por reposição diária da água perdida e estimada por pesagem em balança eletrônica até o estabelecimento das plantas.

Após dois meses de crescimento das plantas, iniciaram-se as exposiçóes ao ambiente contaminado com $\mathrm{F}$ dentro de duas câmaras de nebulização com $2,4 \mathrm{~m}$ de comprimento x 1,5 m de largura x 2,2 m de altura, com volume total de $7,92 \mathrm{~m}^{3}$ e capacidade para oito vasos cada uma. As câmaras foram montadas com tubos PVC de $5 \mathrm{~cm}$ de diâmetro, fechada no topo e nas laterais com filme de polietileno transparente com tratamento antiultravioleta. $\mathrm{Na}$ parte superior foi acoplado um nebulizador compacto (mod. Pulmosonic Star, Soniclear, São Paulo, SP) para aplicação e distribuição do $\mathrm{F}$ no ar, na forma de ácido fluorídrico (HF). O nebulizador foi um gerador ultrassônico de micro partículas homogêneas em forma de aerossol, que transformou aproximadamente $80 \%$ da solução depositada em partículas menores que $4 \mu \mathrm{m}$. Essas partículas evaporam rapidamente gerando pressão de vapor do gás flúor no interior da câmara. $\mathrm{Na}$ parte superior interna da câmara, foi instalada uma tela de malha fina $(0,87 \times 0,30 \mathrm{~mm})$, para formação de uma antecâmara, para prevenir a injúria das folhas pelo contato direto de eventuais microgotas formadas no processo de nebulização do HF. Na parte imediatamente inferior, em posição diagonal, foram acoplados dois ventiladores (mod. Personal Farm, Fame, São Paulo, SP) de $18 \mathrm{~cm}$ de diâmetro, com três pás movimentando a 800 rpm, para circulação do ar em baixa velocidade e distribuição homogênea do F no interior da câmara, conforme descrito em Mesquita et al. (2011). 
Foram utilizados dois delineamentos experimentais, em esquema inteiramente casualisado para azevém, gladíolo e capim-colonião, e fatorial completo para as cultivares de milho, uma exposição ao $\mathrm{F}$ atmosférico $(0,16$ mol L $\mathrm{L}^{-1}$ de $\mathrm{HF}$ ), mais plantas controles não expostas ao ambiente contaminado, com quatro repetiçóes. A concentração da solução de HF e o ciclo de exposição das plantas nas câmaras de nebulização foram definidos em ensaios que indicaram ser suficientes para causar danos à bioindicadora sensível e quase ou nenhum dano àquela tolerante. Quatorze plantas, duas de cada espécie/cultivar, foram fechadas no interior das câmaras (sete em cada câmera) e nebulizadas com $0,16 \mathrm{~mol} \mathrm{~L}^{-1}$ de $\mathrm{HF}(=0,20$ mmol m${ }^{-3} \mathrm{de} \mathrm{F}$ ), durante 30 minutos e, após esse tempo, as plantas permaneceram nas câmaras por mais 60 minutos até a remoção para o ambiente externo. As exposiçôes ocorreram em dias alternados e após a retirada das plantas das câmaras outras eram colocadas até que todas as quatro repetiçóes fossem nebulizadas. A temperatura no interior da câmara foi comparável àquela do ambiente externo, aproximadamente $25-30{ }^{\circ} \mathrm{C}$.

Aos 2, 7 e 20 dias após o início das nebulizaçôes, amostras de folhas totalmente expandidas, sem sintomas visuais, do terço médio das plantas foram coletadas para determinação da clorofila pelo método empregado por Barnes et al. (1992), utilizando dimetilsulfóxido (DMSO) para produçáo do extrato líquido. Os teores de clorofilas a, b e total foram determinados por espectrofotômetro de duplo feixe (mod. U-2000, Hitachi Ltd., Japão) a $646 \mathrm{~nm}$ e $663 \mathrm{~nm}$, e avaliado com base nas equações descrita por Whiтнам et al. (1971), $\mathrm{C}_{\mathrm{a}}=\left(12,7 \mathrm{~A}_{663}\right)$ - $\left(2,69 \mathrm{~A}_{646}\right), \mathrm{C}_{\mathrm{b}}=\left(22,9 \mathrm{~A}_{646}\right)-\left(4,68 \mathrm{~A}_{663}\right) \mathrm{e}_{\mathrm{t}}=\mathrm{C}_{\mathrm{a}}+\mathrm{C}_{\mathrm{b}}$. No mesmo período foram feitas avaliaçôes da ocorrência de sintomas visuais causados pela toxicidade por F, medindo a área total da folha e da parte necrosada, subtraindo a segunda da primeira, para obter a área foliar afetada pelo poluente.

Após a etapa de exposição controlada ao $\mathrm{F}$, as plantas foram coletadas e separadas em raízes, colmos ou hastes e folhas recém-maduras, com lâmina foliar completamente expandida. Para o milho as folhas velhas também foram coletadas. Em seguida, o material vegetal foi lavado com água deionizada e levado para secar em estufa a $65^{\circ} \mathrm{C}$ até obtençâo de massa constante. As amostras secas foram pesadas, moídas e submetidas à análise química para determinaçáo dos teores de $\mathrm{F}$, pelo método recomendado por Frankerberger et al. (1996) e adaptado por Cantarella e Abreu $\left({ }^{1}\right)$. A adaptação refere-se à preparação do ajuste da força iônica total com solução-tampão (TISAB) e o uso de uma curva-padrão de F no lugar da adição do método-padrão para o cálculo de F na amostra. Quinhentos miligramas de amostras secas e moídas foram pesadas em cadinhos de níquel, umedecido com água deionizada e misturadas com $6 \mathrm{~mL}$ de solução de $\mathrm{NaOH} 17 \mathrm{~mol} \mathrm{~L}^{-1}$. $\mathrm{O}$ cadinho foi levado até a temperatura de $600{ }^{\circ} \mathrm{C}$ durante 30 minutos para permitir a fusão da amostra. Após o resfriamento, $10 \mathrm{~mL}$ de água foram adicionados e o produto da fusão foi reaquecido até dissolução. Ajustou-se o $\mathrm{pH}$ para 8-9 com $6 \mathrm{~mol} \mathrm{~L}^{-1}$ de $\mathrm{HCl}$. A solução resultante foi filtrada através de papel de filtro Whatman (n. $\left.{ }^{\circ} 40\right)$. Uma alíquota de $25 \mathrm{~mL}$ do filtrado foi transferido para um frasco de polietileno de $150 \mathrm{~mL}$ e adicionado $25 \mathrm{~mL}$ de TISAB. O pH foi novamente ajustado para 5,2, procedimento feito também para as amostras referencias. As amostras foram medidas utilizando um eletrodo íon-sensível (mod. 60.502.150, Metrohm, Suíça), acoplado a um ionmeter (mod. 692, Metrohm, Suíça), contra uma curvapadrão. Para assegurar a qualidade das análises de F foram utilizadas amostras-controle de grama Timóteo (SRM 2695, do National Institute of Standards and Technology - NIST, Gaithersburg, EUA, contendo $64 \pm 8 \mathrm{mg} \mathrm{kg}^{-1} \mathrm{e}$ $277 \pm 27 \mathrm{mg} \mathrm{kg}^{-1}$ do elemento).

Os dados obtidos foram submetidos à análise de variância pelo teste $\mathrm{F}$ e os efeitos dos tratamentos avaliados por meio de comparação de médias das quatro repetiçóes pelo teste de Duncan a 5\% utilizando o pacote estatístico SAS ${ }^{\circledR}$.

\section{RESULTADOS E DISCUSSÃO}

\section{Concentração de flúor nas folhas e sintomas visuais da toxicidade}

Nas concentraçôes de F nas folhas das plantas-controle das diferentes espécies e cultivares estudadas, os teores de $\mathrm{F}$ foram inferiores a $30 \mathrm{mg} \mathrm{kg}^{-1}$ na massa seca (Figuras 1 e 2), considerado como padráo de referência para proteção de espécies sensíveis ao fluoreto (TREshow e Anderson, 1989).

Por outro lado, a exposição ao F causou ao gladíolo, bioindicador sensível, aumento do teor foliar até cerca de $50 \mathrm{mg} \mathrm{kg}^{-1}$ no fim de 32 dias (Figura 1a). A evoluçáo de sintomas visíveis da toxicidade do elemento ocorreu a partir das folhas mais novas das plantas, já aos dois dias do início das nebulizaçôes na câmara, os quais se caracterizaram pelo aspecto murcho na ponta da lâmina e pela descoloração do tecido (Figura 3a). Esta alteração se estendeu rapidamente, após aproximadamente 5 horas, para margens e regióes internervais da folha, seguida de necrose de cor palha (Figura 3b) e presença de manchas, cuja coloração amarronzada (Figura 3c) decorreu provavelmente da oxidação de compostos fenólicos acumulados no tecido, conforme observado por ForNASIERO (2003).

(') Cantarella, H.; Abreu, M.F. Protocolo analítico para análise de flúor em amostras vegetais: métodos internos do Laboratório de Análise de Solo e Planta. Campinas: Instituto Agronômico, s.d. 
No fim do experimento, aproximadamente $70 \%$ da área foliar do gladíolo estava necrosada.

Para o azevém, bioindicador tolerante, foram observados teores até de $110 \mathrm{mg} \mathrm{kg}^{-1}$ de $\mathrm{F}$ nas folhas das plantas expostas ao F (Figura 1a), sem que houvesse manifestação de danos visuais. Contudo, Mesquita et al. (2011) verificaram pequenas alteraçóes anatômicas na ausência de danos visuais, principalmente a ocorrência de perda no contorno das paredes celulares, além da retração do parênquima lacunoso quando esta espécie foi submetida à contaminaçáo pelo $\mathrm{F}$.

No capim-colonião, verificaram-se teores foliares de $60 \mathrm{mg} \mathrm{kg}^{-1}$ de F nas plantas expostas ao HF (Figura 1c). Sintomas visuais da toxicidade nas folhas ocorreram a partir de 14 dias do início das nebulizaçóes; aquelas superiores, mais expostas ao sol, mostraram lesôes na nervura mediana (Figura 3d), que se espalharam por toda a lâmina até atingir a borda (Figura 3e). Aos 30 dias das (a)

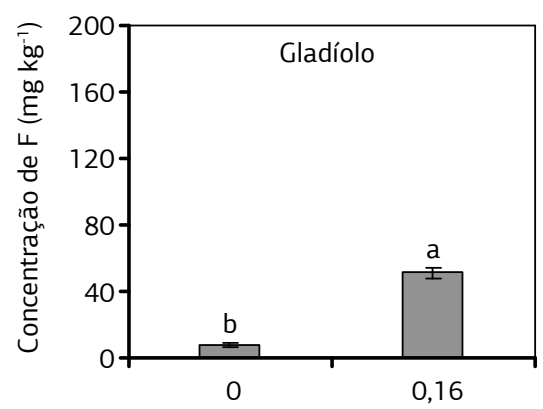

(b)

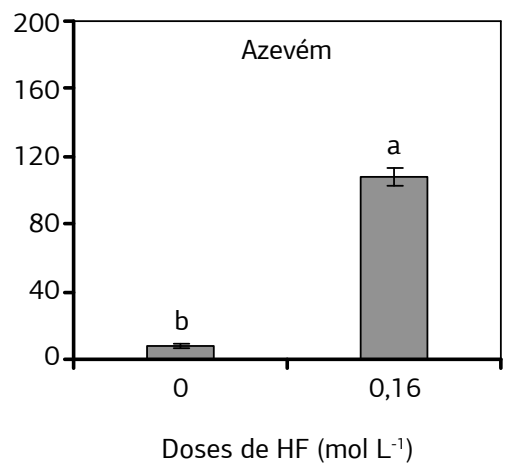

(c)

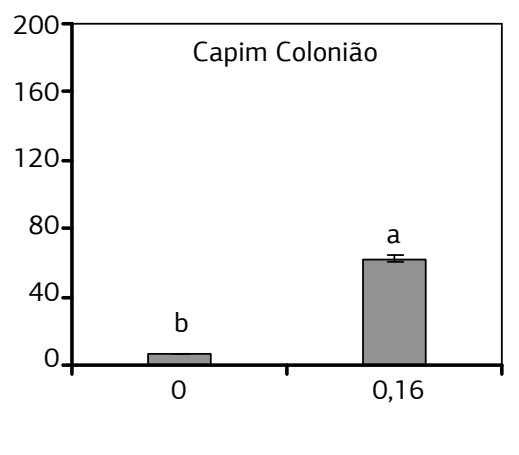

Figura 1. Concentração de flúor nas folhas de plantas de azevém, gladíolo e capim-colonião 32 dias após o início da exposição ao HF em câmara de nebulização. Médias seguidas por letras distintas para cada espécie diferem estatisticamente a 5\% de probabilidade pelo teste de Duncan. Barras nas colunas: erro-padrão.

(a)

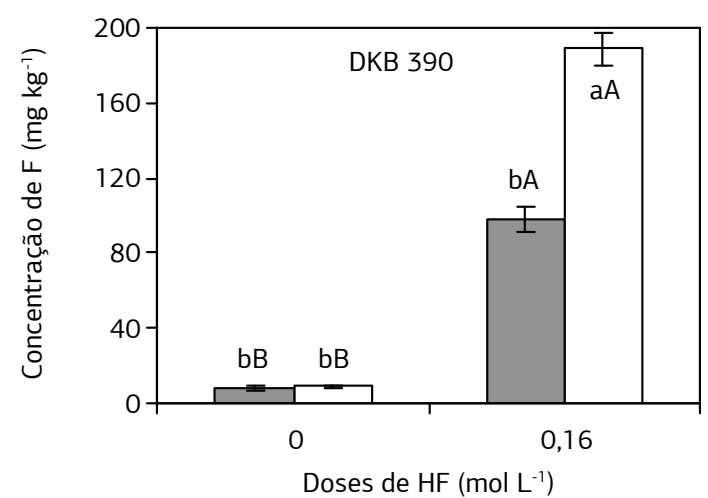

(c)

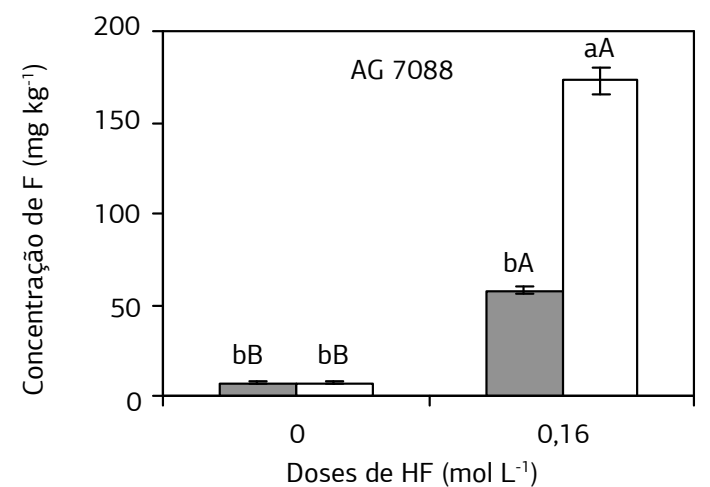

(b)

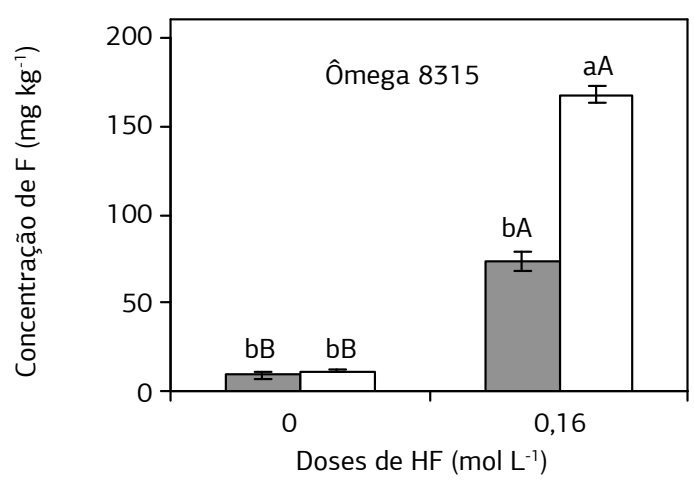

(d)

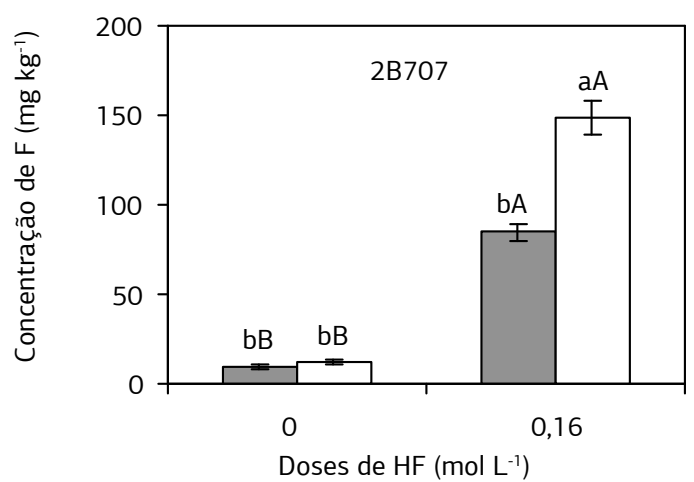

Figura 2. Concentração de flúor nas folhas novas (ロ) e velhas ( $\square$ ) das plantas de milho DKB 390, Ômega 8315, AG 7088 e 2B 707, 32 dias após o início da exposição ao HF em câmara de nebulização. Médias seguidas por letras distintas para cada espécie diferem estatisticamente a $5 \%$ de probabilidade pelo teste de Duncan. 
nebulizaçóes, houve intensificação do sintoma, com surgimento de necroses (Figura 3f). $\mathrm{O}$ capim-colonião foi considerado sensível à toxicidade pelo $\mathrm{F}$ sob chuva contaminada, uma vez que havia $180 \mathrm{mg} \mathrm{kg}^{-1}$ do elemento nas folhas, teor bastante superior àquele encontrado para o azevém e para outras diversas gramíneas tropicais nas mesmas condições; os sintomas visuais característicos causados por este poluente desenvolveram-se rapidamente (Oliva e Figueiredo, 2005). No presente estudo, embora o teor foliar de $\mathrm{F}$ observado para o capim-colonião tenha sido menor comparado ao azevém (Figura 1), os sintomas nas folhas foram semelhantes àqueles reportados por Oliva e Figueiredo (2005); esse fato indica que mesmo não tendo contato direto do elemento, como o fluoreto de potássio (KF), com o tecido foliar, esta espécie é de alta suscetibilidade ao F. Esta suscetibilidade está provavelmente associada a prejuízos devido ao aumento da permeabilidade iônica da membrana celular no tecido foliar, com teores até de $40 \mathrm{mg} \mathrm{kg}^{-1}$ de F, para plantas em área de monitoramento ambiental onde a concentração do $\mathrm{F}$ atmosférico foi registrada entre 0,3-0,6 $\mathrm{mmol} \mathrm{m}^{-3}$ (Divan JR. et al., 2007).

As cultivares de milho possuem teores de $60-100$ $\mathrm{mg} \mathrm{kg}^{-1}$ de $\mathrm{F}$ nas folhas novas e de $150-190 \mathrm{mg} \mathrm{kg}^{-1}$ de $\mathrm{F}$ nas folhas velhas quando expostas ao HF, o que decorreu de forma proporcional ao tempo em que estiveram sujeitas ao ambiente contaminado durante o desenvolvimento do experimento (Figura 2). Segundo Coulter et al. (1985), o acúmulo de $\mathrm{F}$ nos tecidos ocorre de forma crônica, o que causa lesões quando altas concentrações são atingidas.

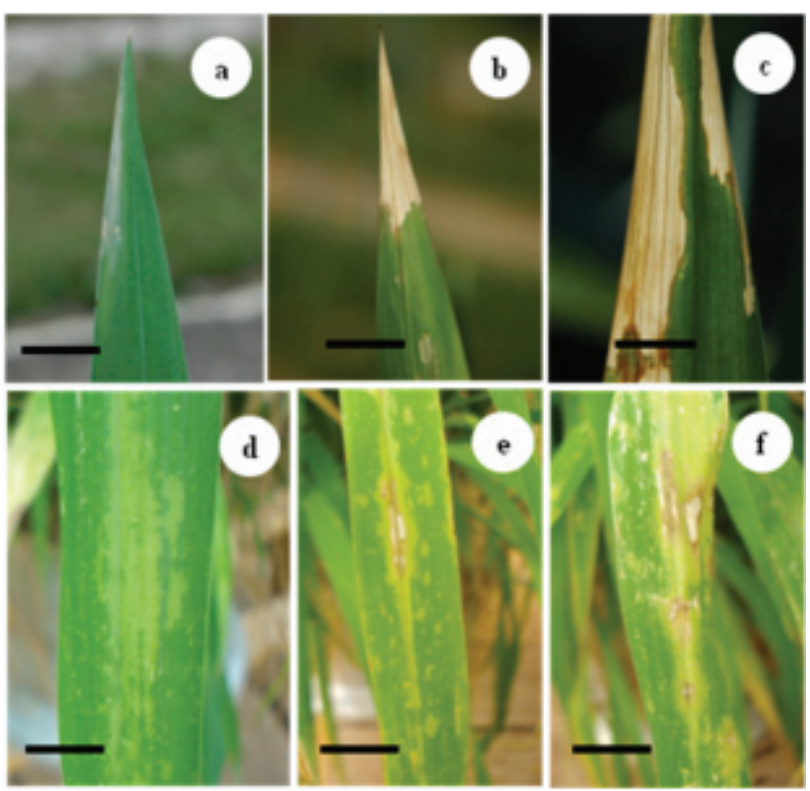

Figura 3. Sintomas de injúrias em folhas causadas pela exposição à alta dose de F em câmara de nebulização: gladíolo (a-c) - iniciando como clorose nas pontas e bordas e progredindo para o interior da folha até se transformar em necrose; capim coloniáo (d-f) iniciando da nervura central e se espalharam até atingir a borda da folha. Avaliaçóes realizadas após 2 (a,d), 7 (b,e) e 20 (c,f) dias da aplicação de F. Barras: 0,2 cm em a,d,e,f; 0,5 cm em b,c.
No caso do milho, teores até de $160 \mathrm{mg} \mathrm{kg}^{-1}$ de $\mathrm{F}$ foram observados em folhas de cultivares de safrinha avaliadas em experimento de campo instalado próximo à indústria produtora de revestimento cerâmicos, cuja severidade dos sintomas devido à toxicidade do elemento variou dependendo do material genético (ForTes et al., 2003).

Embora não se tenha verificado interação entre tratamentos e cultivares para os teores foliares de $\mathrm{F}(\mathrm{p}<0,05)$, sintomas visuais da toxicidade causada pelo elemento foram observados como cloroses nas bordas das folhas a partir de sete dias do início das nebulizaçóes para DKB 390 (Figura 4a-b) e Ômega NBX 8315 (Figura 4d-e), consideradas sensíveis,

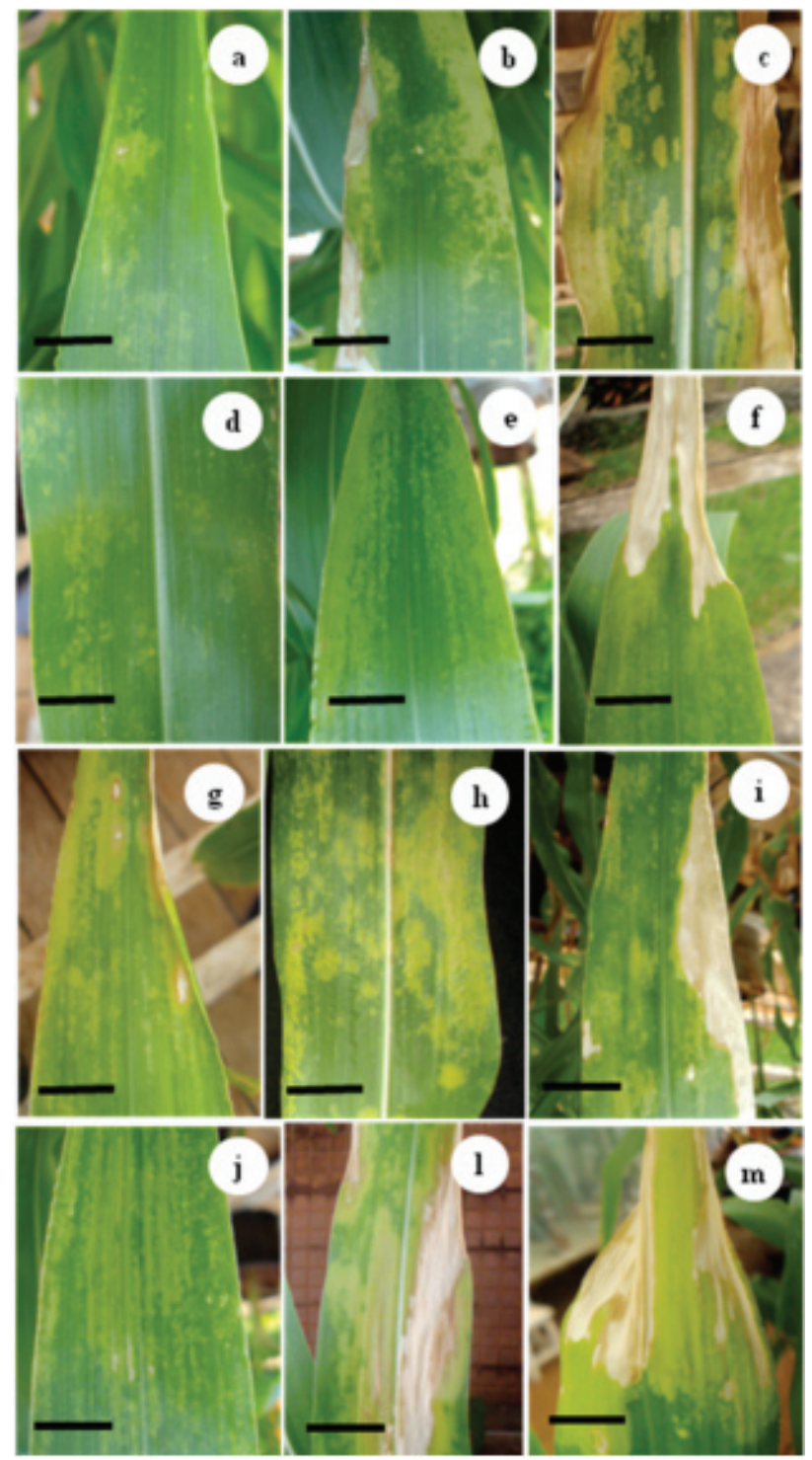

Figura 4. Sintomas de injúrias em folhas de milho causadas pela exposição à alta dose de $\mathrm{F}$ em câmara de nebulização: DKB 390 (a-c) iniciando da borda e progredindo para o interior da folha, até se transformar em uma necrose de coloração palha; Ômega NBX 8315 (d-f) iniciando pelas bordas e progredindo para a nervura central da folha; AG 7088 (g-i) clorose em toda a lâmina que progrediu para necrose na borda foliar; 2B 707 ( $\mathrm{j}-\mathrm{m})$ iniciando da borda e progredindo para o interior da folha. Avaliaçóes realizadas após 7 (a,d,g,j), 15 (b,e,h,l) e 30 (c,f,i,m) dias da aplicação de F. Barras: 0,15 cm em a-c; 0,5 cm em d-f; 0,2 cm g-m. 
que evoluíram para uma necrose marginal com aumento da exposição ao HF (Figura 4c, f). Nas cultivares AG 7088 e 2B 707, tolerantes, os sintomas apareceram pouco antes do florescimento, dez dias após o início da nebulização, com ocorrência de clorose internerval das folhas mais expostas ao sol (Figura 4g-h, j-l) que evoluíram para necrose marginal das folhas na maturação dos grãos, 25 dias após o início das nebulizaçōes (Figura 4i, m).

\section{Teor de clorofila nas folhas}

Os teores de clorofila a, b e total para o gladíolo diminuíram proporcionalmente cerca de $50 \%$ nas plantas expostas ao $\mathrm{F}$, o que pode ser associado à rápida descoloração do tecido foliar causado pela oxidação de complexos enzimáticos responsáveis pela biossíntese da clorofila (Weinstein, 1977).

Por outro lado, os teores de clorofila para o azevém e o capim-colonião não foram afetados (Tabela 1). Embora no capim-colonião tenha ocorrido sintomas visuais pouco severos causados pela contaminaçáo atmosférica depois de sete dias do início das nebulizaçôes na câmara, nota-se que os segmentos das folhas amostrados para determinaçáo da clorofila no presente estudo estavam sem sintomas visuais. Para as plantas de gladíolo, foram retirados trechos das folhas que estavam sem sintomas. Nesta condição, cujo efeito cumulativo do $\mathrm{F}$ ainda náo foi significativo, é possível que o efeito da poluição atmosférica se assemelhe às exposiçóes pouco prolongadas ( $<8$ dias) como observado para o capim-colonião em condiçốes de campo, cujo estudo ainda demonstrou não haver decréscimos nos teores de clorofila a e b e na razão a:b nas folhas das plantas com

Tabela 1. Teores de clorofila em azevém, gladíolo e capim-colonião determinados em amostras sem sintomas visuais do tecido foliar após 30 dias de exposição ao $\mathrm{F}$ em câmara de nebulização

\begin{tabular}{|c|c|c|c|}
\hline \multirow[t]{2}{*}{$\begin{array}{l}\text { Doses de HF } \\
\left(\mathrm{mol} \mathrm{L}^{-1}\right)\end{array}$} & $\begin{array}{l}\text { Clorofila a } \\
\left(\mathrm{mg} \mathrm{g}^{-1}\right)\end{array}$ & $\begin{array}{c}\text { Clorofila b } \\
\left(\mathbf{m g ~ g}^{-1}\right)\end{array}$ & $\begin{array}{c}\text { Clorofila total } \\
\left(\mathbf{m g ~ g}^{-1}\right)\end{array}$ \\
\hline & \multicolumn{3}{|c|}{ Gladíolo } \\
\hline 0 & $1,38 \mathrm{a}$ & $0,38 \mathrm{a}$ & $1,77 \mathrm{a}$ \\
\hline 0,16 & $0,69 b$ & $0,20 \mathrm{~b}$ & $0,89 \mathrm{~b}$ \\
\hline Média & 1,04 & 0,29 & 1,33 \\
\hline \multirow[t]{2}{*}{ CV(\%) } & 13,09 & 12,20 & 12,83 \\
\hline & \multicolumn{3}{|c|}{ Azevém } \\
\hline 0 & $1,86 \mathrm{a}$ & $0,56 \mathrm{a}$ & $2,42 \mathrm{a}$ \\
\hline 0,16 & $1,92 \mathrm{a}$ & $0,56 \mathrm{a}$ & $2,47 \mathrm{a}$ \\
\hline Média & 1,88 & 0,56 & 2,45 \\
\hline \multirow[t]{2}{*}{ CV(\%) } & 7,65 & 8,70 & 7,78 \\
\hline & \multicolumn{3}{|c|}{ Capim-colonião } \\
\hline 0 & $1,55 \mathrm{a}$ & $0,38 a$ & $1,92 \mathrm{a}$ \\
\hline 0,16 & $1,56 \mathrm{a}$ & $0,41 \mathrm{a}$ & $1,97 \mathrm{a}$ \\
\hline Média & 1,57 & 0,39 & 1,95 \\
\hline CV(\%) & 14,93 & 16,50 & 15,15 \\
\hline
\end{tabular}

Médias seguidas por letras distintas para cada espécie diferem estatisticamente a 5\% de probabilidade pelo teste de Duncan. teores foliares totais de $\mathrm{F}$ até cerca de $70 \mathrm{mg} \mathrm{kg}^{-1}$ (Divan JR. et al., 2007).

Houve redução de $42 \%$ dos teores de clorofila a para a cultivares AG 7088, 24\% para a 2B707 e 20\% para a DKB 390 (Tabela 2) quando as plantas foram expostas ao F; os prejuízos foram relacionados a danos na atividade fotossintética e ao metabolismo de carboidrato das plantas, levando à queda de produção (RATHORE, 1992). Ainda, destaca-se que plantas sujeitas à contaminaçáo com o $\mathrm{F}$ atmosférico podem ter menor síntese e maior degradação da clorofila a em relação à clorofila b (LAL e AMBASHT, 1981; Ivinskis e MurraY, 1984). Os efeitos metabólicos causados sobre as plantas podem ser explicados devido à interação do $\mathrm{F}$ com o magnésio $(\mathrm{Mg})$, uma vez que este último está presente na pectina da parede celular e em quantidade maior que 50\% nos cloroplastos (Marschner, 1995). Assim, a formação de compostos, como $\mathrm{MgF}_{2}$, causa desestruturação na parede e

Tabela 2. Teores de clorofila $\left(\mathrm{mg} \mathrm{g}^{-1}\right)$ em cultivares de milho determinados em amostras sem sintomas visuais do tecido foliar após 30 dias de exposição ao $\mathrm{F}$ em câmara de nebulização

\begin{tabular}{|c|c|c|c|c|}
\hline \multirow{2}{*}{$\begin{array}{l}\text { Cultivares/ } \\
\text { Doses de HF } \\
\left(\mathrm{mol} \mathrm{L}^{-1}\right)\end{array}$} & \multicolumn{2}{|c|}{$\begin{array}{c}\text { Clorofila } \\
\mathbf{a}\end{array}$} & $\begin{array}{c}\text { Clorofila } \\
\text { b }\end{array}$ & $\begin{array}{c}\text { Clorofila } \\
\text { total }\end{array}$ \\
\hline & 0 & 0,16 & 0,16 & 0,16 \\
\hline DKB 390 & 1,62 a $A$ & 1,26 a $A B$ & 0,330 & $1,76 \mathrm{AB}$ \\
\hline Ômega 8315 & 1,57 a $A$ & 1,55 a $A$ & 0,367 & $1,93 \mathrm{~A}$ \\
\hline AG 7088 & 1,45 a $A B$ & 0,84 b B & 0,295 & $1,46 \mathrm{~B}$ \\
\hline 2B707 & 1,36 a B & 1,03 b B & 0,278 & $1,48 \mathrm{~B}$ \\
\hline Média & - & - & - & 1,86 a $1,45 b$ \\
\hline
\end{tabular}

Médias seguidas por letras distintas para cada espécie (dentro da mesma cultivar) diferem estatisticamente a $5 \%$ de probabilidade pelo teste de Duncan.

Tabela 3. Produção de massa seca em gladíolo, azevém e capimcolonião após 32 de exposição ao $\mathrm{F}$ em câmara de nebulizaçáo

\begin{tabular}{|c|c|c|c|c|}
\hline $\begin{array}{l}\text { Doses de } \\
\text { HF } \\
\left(\mathrm{mol} \mathrm{L}^{-1}\right)\end{array}$ & $\begin{array}{l}\text { MSPA } \\
(\mathrm{g})\end{array}$ & $\begin{array}{c}\text { MSR } \\
\text { (g) }\end{array}$ & $\begin{array}{c}\text { MST } \\
\text { (g) }\end{array}$ & $\begin{array}{l}\text { MSR/ } \\
\text { MSPA }\end{array}$ \\
\hline & \multicolumn{4}{|c|}{ Gladíolo } \\
\hline 0 & $33,30 \mathrm{a}$ & $29,36 a$ & $62,66 \mathrm{a}$ & $0,89 a$ \\
\hline 0,16 & $26,97 \mathrm{~b}$ & $14,94 b$ & $41,91 \mathrm{~b}$ & $0,56 \mathrm{~b}$ \\
\hline Média & 30,14 & 22,15 & 52,29 & 0,73 \\
\hline \multirow[t]{2}{*}{ CV(\%) } & 15,12 & 17,31 & 12,62 & 20,55 \\
\hline & \multicolumn{4}{|c|}{ Azevém } \\
\hline 0 & $32,61 \mathrm{a}$ & $33,63 \mathrm{a}$ & $66,24 \mathrm{a}$ & $1,06 \mathrm{a}$ \\
\hline 0,16 & $28,37 \mathrm{a}$ & $30,07 \mathrm{a}$ & $58,48 \mathrm{~b}$ & $1,03 \mathrm{a}$ \\
\hline Média & 30,49 & 31,85 & 62,34 & 1,05 \\
\hline \multirow[t]{2}{*}{ CV(\%) } & 7,63 & 6,28 & 10,12 & 7,54 \\
\hline & \multicolumn{4}{|c|}{ Capim-colonião } \\
\hline 0 & $116,76 \mathrm{a}$ & $86,88 \mathrm{a}$ & $203,64 \mathrm{a}$ & $0,74 a$ \\
\hline 0,16 & $109,93 \mathrm{a}$ & $53,12 b$ & $163,05 \mathrm{~b}$ & $0,48 b$ \\
\hline Média & 113,34 & 70,00 & 183,34 & 0,61 \\
\hline CV(\%) & 5,16 & 12,5 & 3,19 & 5,55 \\
\hline
\end{tabular}

Médias seguidas por letras distintas para cada espécie diferem estatisticamente a 5\% de probabilidade pelo teste de Duncan. MSPA = massa seca da parte aérea; MSR = massa seca da raiz; $\mathrm{MST}=$ massa seca total da planta. 
Tabela 4. Produção de massa seca (g) por cultivares de milho após 32 dias de exposição ao F em câmara de nebulização

\begin{tabular}{|c|c|c|c|c|c|c|c|c|}
\hline \multirow{2}{*}{$\begin{array}{l}\text { Cultivares/Doses } \\
\left.\text { de HF ( } \mathrm{mol} \mathrm{L}^{-1}\right)\end{array}$} & \multicolumn{2}{|c|}{ MSPA } & \multicolumn{2}{|c|}{ MSR } & \multicolumn{2}{|c|}{ MST } & \multicolumn{2}{|c|}{ MSR/MSPA } \\
\hline & 0 & 0,16 & 0 & 0,16 & 0 & 0,16 & 0 & 0,16 \\
\hline DKB 390 & $94,3 \mathrm{~A} \mathrm{~b}$ & $76,3 \mathrm{~B} \mathrm{~b}$ & \multicolumn{2}{|c|}{$19,1 \mathrm{~b}$} & \multicolumn{2}{|c|}{104,4 b } & $0,25 \mathrm{Ac}$ & $0,19 A C$ \\
\hline Ômega 8315 & $107,7 \mathrm{~A} \mathrm{a}$ & $88,2 \mathrm{~B} \mathrm{a}$ & \multicolumn{2}{|c|}{$17,5 \mathrm{~b}$} & \multicolumn{2}{|c|}{$115,5 a b$} & $0,19 \mathrm{Ad}$ & $0,16 \mathrm{~B} \mathrm{C}$ \\
\hline AG 7088 & $98,7 \mathrm{~A} \mathrm{~b}$ & $86,8 \mathrm{~B} \mathrm{a}$ & \multicolumn{2}{|c|}{$28,4 \mathrm{a}$} & \multicolumn{2}{|c|}{$121,2 \mathrm{a}$} & $0,32 \mathrm{Ab}$ & $0,29 \mathrm{~A} \mathrm{a}$ \\
\hline 2B707 & $92,7 \mathrm{~A} \mathrm{~b}$ & $86,7 \mathrm{~B} \mathrm{a}$ & \multicolumn{2}{|c|}{$27,3 a$} & \multicolumn{2}{|c|}{$117,0 \mathrm{ab}$} & $0,36 \mathrm{~A} \mathrm{a}$ & $0,24 \mathrm{~B} \mathrm{~b}$ \\
\hline Média & - & - & $27,3 \mathrm{~A}$ & $18,9 \mathrm{~B}$ & $125,6 \mathrm{~A}$ & 103,4 B & - & - \\
\hline
\end{tabular}

Médias seguidas por mesma letra minúscula nas colunas e por mesma letra maiúscula nas linhas (dentro do mesmo componente da massa seca) nẫo diferem a $5 \%$ pelo teste de Duncan para cultivares. MSPA = massa seca da parte aérea; $\mathrm{MSR}$ = massa seca da raiz; $\mathrm{MST}=$ massa seca total da planta.

distúrbios na biossíntese da clorofila e na atividade da rubisco (Parry et al., 1984; Weinstein e Davison, 2004). Para Ômega 8315, não foram verificados os mesmos prejuízos, e esta foi a cultivar com o maior teor de clorofila total entre aquelas estudadas $\left(=1,93 \mathrm{mg} \mathrm{g}^{-1}\right.$; Tabela 1$)$.

\section{Produção de massa seca}

As produçóes de massa seca pelo gladíolo e capim-colonião foram afetadas pelo $\mathrm{F}$ atmosférico, com redução na razão massa seca de raízes: massa seca da parte aérea (MSR/MSPA) de 0,80 nas plantas-controle para 0,50 naquelas mantidas na câmara de nebulizaçáo por 32 dias, o que não foi verificado para o azevém, cuja MSR/ MSPA foi de aproximadamente 1,00 (Tabela 3). Oliva e Figueiredo (2005) descreveram o capim-coloniáo como uma gramínea de crescimento rápido. Neste trabalho, os autores ainda destacam que mais de $90 \%$ do $\mathrm{F}$ total nas plantas foram encontrados na parte aérea das plantas (soca + rebrota) e houve redução da taxa de fotossíntese de $12 \mu \mathrm{mol} \mathrm{m}{ }^{-2} \mathrm{~s}^{-1}$ para $2 \mu \mathrm{mol} \mathrm{m} \mathrm{m}^{-2} \mathrm{~s}^{-1}$ para as plantas expostas à chuva contaminada com o F. Nesta condição, a produção de açúcares totais, açúcares redutores e amido nas folhas diminui (Divan Jr. et al., 2007) e, consequentemente, a distribuição para o sistema radicular, o que explicaria o decréscimo acentuado na produção de raízes como observado neste trabalho.

Nas cultivares de milho DKB 390 e Ômega NBX 8315 houve maior suscetibilidade ao F, com base na menor produção de massa seca das plantas, em relação a AG 7088 e 2B 707 (Tabela 4), o que confirma as informaçôes técnicas reportadas por DuARTe et al. (2009) em campos de avaliação de desempenho agronômico do milho safrinha. Destaca-se que a variação da razão MSR/MSPA em função da exposição do contaminante para o milho mostrou menor sensibilidade à toxicidade $(<30 \%)$ se comparado àquela do capim-colonião (>35\%) (Tabelas 3 e 4).

Embora as cultivares AG 7088 e 2B 707 tenham proporcionado reduçóes mais significativas dos teores de clorofila (Tabela 2), é possível que, dada a característica do tecido foliar amostrado para análise (discutido anteriormente), não se tenha evidenciado a extensão total dos prejuízos causados pelo $\mathrm{F}$ e que explicassem os menores prejuízos à produçáo de massa das plantas. Assim, deve-se considerar que a maior ocorrência de áreas necrosadas nas folhas das cultivares DKB e Ômega (Figura 4) que se seguiu à degradação da clorofila tenha afetado a assimilação total de carbono pela redução da área fotossinteticamente ativa e, consequentemente, o crescimento das plantas no fim do período de estudo (Doley, 2010).

\section{CONCLUSÃO}

A exposição das plantas ao flúor atmosférico causou o aumento da concentração do elemento nas folhas até $60 \mathrm{mg}$ $\mathrm{kg}^{-1}$ para o gladíolo e o capim-colonião, $100 \mathrm{mg} \mathrm{kg}^{-1}$ para o azevém e entre $100 \mathrm{mg} \mathrm{kg}^{-1}$ e $170 \mathrm{mg} \mathrm{kg}^{-1}$, respectivamente, nas folhas novas e velhas, para as cultivares de milho, o que demonstrou o efeito cumulativo da contaminação. As cultivares DKB 390 e Ômega 8315 foram mais sensíveis ao $\mathrm{F}$, quando comparadas às AG7088 e 2B707. Na análise de clorofilas, o teor da clorofila a nas plantas se destacou como o mais afetado pelo F, com exceção ao azevém, com diferentes respostas para as cultivares de milho.

\section{AGRADECIMENTOS}

À Fundação de Amparo à Pesquisa do Estado de São Paulo pelo apoio financeiro (Proc. 2008/09541-6), e ao CNPq/ PIBIC/IAC (Proc. 12.213/2008) pela concessão da bolsa de iniciação científica à primeira autora.

\section{REFERÊNCIAS}

ARNDT, U.; FLORES, F; WEINSTEIN, L.H. Fluoride effects on plants, diagnose of injury in the vegetation of Brazil. Porto Alegre: UFRGS, 1995. 155p.

BARNES, J. D.; BALUGUER, L.; MANRIQUE, E.; ELVIRA, S.; DAVISON, A.W. A reappraisal of the use of DMSO for the extraction and determination of chlorophylls $\mathrm{a}$ and $\mathrm{b}$ in lichens and higher plants. Environmental and Experimental Botany, v.32, p.85-100, 1992.

BUSTAMANTE, M.; OLIVA, M.A.; SANT'ANNA, R.; LOPES, N.F. Sensibilidade da soja ao flúor. Revista Brasileira de Fisiologia Vegetal, v.5, p.151-157, 1993. 
COULTER, C.T.; PACK, M.R.; SULZBACH, C.W. An evaluation of the dose-response relationship of fluoride injury to Gladiolus. Atmospheric Environment, v.19, p.1001-1007, 1985.

DIVAN Jr, A.M.; OLIVA, M.A.; MARTINEZ, C.A.; CAMBRAIA, J. Effects of fluoride emissions on two tropical grasses: Chloris gayana and Panicum maximum, cv. Colonião. Ecotoxicology and Environmental Safety, v.67, p.247-253, 2007.

DOLEY, D. Rapid quantitative assessment of visible injury to vegetation and visual amenity effects of fluoride air pollution. Environmental Monitoring and Assessment, v.160, p.181-198, 2010.

DUARTE, A.P.; CANTARELLA, H.; OTA, E.C. Efeito colateral. Revista Cultivar, v.117, p.6-8, 2009.

FORNASIERO, R.B. Fluorides effects on Hypericum perforatum plants: first field observations. Plant Science, v.165, p.507-513, 2003.

FORTES, C.; DUARTE, A.P.; MATSUOKA, S.; HOFFMANN, H.P.; LAVORENTI, N.A. Toxicidade de flúor em culturas de milho em áreas próximas a uma indústria cerâmica, Araras, SP. Bragantia, v.62, p.275-281, 2003.

FRANKENBERGERJR., W.T.; TABATABAI, M.A.; ADRICANO, D.C.; DONER, H.E. Bromine, chlorine, and fluorine. p.833867. In: BINGHAM, J.M. (Ed.). Methods of Soil Analysis. Part 3. Chemical Methods. Madison: Soil Science Society of America. 1996. 139p. (SSSA Book Series, 5)

FRANZARING, J.; KLUMPP, A.; FRANGMEIER, A. Active biomonitoring of airborne fluoride near an HF producing factory using standardized grass cultures. Atmospheric Environment, v.41, p.4828-4840, 2007.

IVINSKIS, M.; MURRAY, F. Associations between metabolic injury and fluoride susceptibility in two species of Eucalyptus. Environmental Pollution, v.34, p.207-223, 1984.

KLUMPP, A.; DOMINGOS, M.; KLUMPP, G. Assessment of the vegetation risk by fluoride emissions from fertilizer industries at Cubatão, Brasil. The Science of the Total Environment, v.192, p.219-228, 1996.

KLUMPP, A.; MODESTO, I.F.; DOMINGOS, M.; KLUMPP, G. Susceptibility of various gladiolus cultivars to fluoride pollution and their suitability for bioindication. Pesquisa Agropecuária Brasileira, v.32, p.239-247, 1997.

LAL, B.; AMBASHT, R.S. Impairment of chlorophyll content in leaves of Diospyros melanoxylon by fluoride pollution. Water, Air and Soil Pollution, v.16, p.361-365, 1981.
MACÊDO, L.S.; MORRIL, W.B.B. Toxidade dos ametais no solo e nas plantas: uma revisão de literatura. Tecnologia e Ciência Agropecuária, v.2, p.39-42, 2008.

MARSCHNER, H. Mineral nutrition of higher plants, 2.ed. London: Academic Press, 1995. 889p.

MESQUITA, G.L.; TANAKA, F.A.O.; CANTARELLA, H.; MATTOS JR., D. Atmospheric absorption of fluoride by cultivated species. Leaf structural changes and plant growth. Water, Air and Soil Pollution, v.219, p.143-156, 2011.

OLIVA, M.A.; FIGUEIREDO, J.G. Gramíneas bioindicadoras da presença de flúor em regióes tropicais. Revista Brasileira de Botânica, v.28, p.389-397, 2005.

OTTO, R.; FARIA, M.R.M.; QUEIROZ, F.E.C.; MOURA, T.A.; VITTI, G.C.; CANTARELLA, H. Rendimento da canade-açúcar é afetado por flúor. Bragantia, v.66, p.505-509, 2007.

PARRY, M.A.J.; SCHMIDT, C.N.G.; GUTTERIDGE, S. Inhibition of ribulose- $\mathrm{P}_{2}$ carboxylase/oxigenase by fluoride. Journal of Experimental Botany, v.35, p.161-198, 1984.

PITA-BARBOSA, A.; SANT'ANNA-SANTOS, B.; SILVA, K.L.F.; AZEVEDO, A.A.; ROCHA, D.I. Eeitos fitotóxicos do fluoreto na morfoanatomia foliar de Bachiaria brizantha (Hochst. Ex A. Rich) e Brachiaria decumbens Stapf (Poaceae). Acta Botânica Brasílica, v.23, p.1027-1033, 2009.

RAIJ, B. van; ANDRADE, J.C.; CANTARELLA, H.; QUAGGIO, J.A. Análise química para avaliação da fertilidade de solos tropicais. Campinas: Instituto Agronômico, 2001. 285p.

RHATORE, S. Effect of fluoride toxicity on leaf area, net assimilation rate and relative growth rate of Hordeum vulgare and Zea mays. Fluoride, v.25, p.171-182, 1992.

SANT'ANNA-SANTOS, B.F.S.; AZEVEDO, A.A. Aspectos morfoanatômicos da fitotoxidez do flúor em duas espécies arbóreas tropicais. Revista Brasileira de Biociências, v.5, p.4850, 2007.

TRESHOW, M.; ANDERSON, F.K. Plant stress from air pollution. New York: John Wiley \& Sons, 1989. 296p.

WEINSTEIN, L.H. Fluoride and plant life. Journal of Occupational Medicine, v.1, p.49-78, 1977.

WEINSTEIN, L.H.; DAVISON, A. Fluoride in the environment. London: Cabi, 2004. 287p. 